Научная статья

УДК 172.16

DOI: $10.18101 / 1994-0866-2020-4-54-60$

\title{
РУИНЫ КОСМОПОЛИТИЧЕСКОГО ДИСКУРСА
}

\author{
(C) Власов Александр Александрович \\ аспирант, \\ Российский государственный гуманитарный университет \\ Россия, 125993, г. Москва, Миусская площадь, 6 \\ mioxin@gmail.com
}

\begin{abstract}
Аннотация. Историческая амбивалентность космополитического проекта и его многоплановое развитие приводят к тому, что в настоящее время единый корпус космополитического дискурса распадается на множественные фракции отчасти противоречащих и контрастирующих между собой подходов, претендующих на то, чтобы считаться космополитическими. Дело не просто в том, что сам по себе космополитизм расщепляется на политический, экономический, моральный, правовой или культурный, но все больше в том, что принимаемая в качестве отправной точки кантианская модель космополитической федерации обнажает все больше критических точек несоответствия заявленной тенденции к универсализму. В это же время современность предъявляет совершенно новые требования к пониманию «космополитического» и таким образом разламывает исходное ядро, деконструируя классическую базу понятий вокруг космополитизма.

Ключевые слова: универсализм; имперский космополитизм; критический космополитизм; космополитизм подчиненных; демократический повтор; перформативное противоречие; дискурс.
\end{abstract}

\section{Для цитирования}

Власов А. А. Руины космополитического дискурса // Вестник Бурятского государственного университета. Философия. 2020. Вып. 4. С. 54-60.

\section{Реалии космополитического дискурса}

Следуя за точкой зрения Эдуардо Мендиетта и развивая таким образом критический анализ классической кантианской модели космополитизма, предложенный Дэвидом Харви, можно сделать вывод о том, что в настоящее время «мы наблюдаем руины вавилонской башни космополитического дискурса» $[10$, с. 241]. Это означает, что дискурс космополитизма распадается на множественные ответвления и градации: элитный, постмодернистский, патриотический, левый, потребительский и т. д. Внутри этой сети накладывающихся друг на друга трактовок можно различить, что космополитизм одних принимает очертания провинциализма в интерпретации других; этическая позиция одной группы космополитов воспринимается как естественная привилегия других; а углубленное осознание воплощается в молчаливое других. Таким образом, в глобальном распространении модифицированных, локализованных и историзированных форм космополитизма есть те противоречия, которые заслуживают того, чтобы их разделить на составляющие части и должным образом рассмотреть. И в этом ключе основной момент 
заключается в том, чтобы установить, какие именно аспекты космополитической идеи по-прежнему отвечают требованию времени и эпохи, а следовательно, должны быть сохранены.

Прежде всего, космополитизм - это способ отношения к миру. Однако возникает вопрос, какова природа этих отношений? Со времен греческих стоиков, средневековых христиан с их универсалистским евангелием, Византийской империи и философов Просвещения быть космополитом означало считать себя гражданином всего мира, что имплицитно было связано с тем, что приверженность отдельного индивидуума должна выражаться скорее по отношению к бо́льшему «мы», нежели к местному политическому и географическому образованию. То есть другой не является чуждым для гражданина мира, космополита. И в этом минималистском определении космополитизма обнаруживается соприкосновение нескольких сил: изначальное признание силы географического положения и местной политической формации; проявление эпистемологической и этической позиции, а также проекция или предвосхищение того, что эта эпистемологическая и моральная точка зрения может превратится в существенный политический проект.

К настоящему моменту можно сказать, что космополитизм скрыто признает силу географической обусловленности, поскольку находится в противоречии с ней. Космополитизм является одновременно как эпистемологическим, так и моральным отношением к историческому миру людей, поскольку он стремится познать и признать человечество во всем, что им было сделано. Таким образом, космополитизм влечет за собой космополитический проект, в котором определенная политико-правовая институциональная структура допускает совместное проживание и взаимное процветание всего, что является единичным, а значит, и различным, и дифференцирующим в рамках единого человеческого сообщества. Это можно выразить более схематично и формализованно, указав на то, что космополитизм - диалектическое взаимодействие между сингулярностью и универсальностью, между точкой на местности и перемещением, между укорененностью и безродностью, домом и бездомностью, статичностью и мобильностью.

\section{Имперское основание космополитизма}

Рассматривая двуликость политического проекта космополитизма, Карл Леви [9] показывает, что изначально этот проект был характерен для империй, городов и разветвленной торговой сети. Это, с одной стороны, указывает на исходное отсутствие каких-либо привилегий в рамках такого проекта, с другой - это же обстоятельство намекает на стремление к постоянному доступу к различным материальным благам и, следовательно, принадлежность к более космополитическим городам, государствам или торговым союзам, что сама по себе становится привилегией. Таким образом, мы сталкиваемся с «наивным» космополитизмом, который по своей сути является формой распространения имперских амбиций, чье отражение обнаруживает себя в кантианской космополитической модели. 
Благодаря анализу кантианской антропологии (Antropology from a Pragmatic Point of View, 1798) и курса лекций по физической географии (Physische Geographie,1796), проведенному Фуко [5] космополитическая идея Канта приобретает все более отчетливые формы имперского проекта западной христианской цивилизации, поскольку подразумевает установление такого рода моральной и политической иерархии, которая основана на понятии способности той или иной культуры удовлетворить требования космополитической законности и политики. Это обстоятельство, согласно мнениям Харви и Мендиетта, делает такой космополитизм несостоятельным для «нашего постметафизического, пост-секулярного, пост-колониального или деколониального контекста» $[10$, с. 244]. В пользу тезиса об империалистическом характере кантианского космополитизма свидетельствует то, как сам Кант описывает характер получения знаний об иных культурах: он указывает на то, что достаточно находится в центре имперского территориального владычества, чтобы получать из книг необходимую информацию о том, что существует на периферии [8, с. 4]. Более того, Харви демонстрирует, каким неприглядным образом рисует Кант аборигенные племена Азии и Африки с тем, чтобы показать незрелость отдельных культур, а следовательно, их невозможность войти в состав федерации суверенных деморатических и республиканских государств, каковыми для него являются западные страны [7]. Таким образом, имперский космополитизм высокомерен, безучастен и автаркичен. Он высокомерен, поскольку отменяет для себя роль измерения того, что является моральной зрелостью и человеческими достижениями. Он безразличен, потому что не принимает во внимание отрицательные последствия своего собственного воздействия на другие культуры и мир в целом, считая их неизбежными и оправданными. Он автаркичен, потому что он не признает, что все человеческие достижения не являются индивидуальными, национальными, расовыми или даже цивилизационными, а принадлежат всему человеческому роду.

\section{Рефлексивный космополитизм}

Другим направлением космополитизма можно назвать рефлексивный космополитизм. В рамках этого направления Марта Нуссбаум, отталкиваясь от кантианской базы, выходит за пределы его евроцентристских, сексистских и расистских допущений, чтобы противопоставить форму гражданского космополитизма ограниченности и поверхностности патриотизма. В этом отношении ее трактовка выглядит более практически ориентированной, так как она делает акцент на необходимости космополитического образования, которое могло бы научить граждан видеть себя в первую очередь членами мирового, а не узких, исключительных сообществ. Получение такого образования и способность мыслить в качестве члена глобального сообщества поднимает эпистемологическую планку того, какие различия и аргументы мы способны приводить. Таким образом, космополитизм Нуссбаум заключается в том, чтобы войти в пространство причин, которое не имеет границ и предположительно не имеет никаких исключающих требований членства. 
Еще одним представителем этой формы космополитизма можно назвать Кваме Энтони Аппийя, который прослеживает две различные оси космополитизма. Одна ось подчеркивает идею о том, что у нас есть обязательства перед другими. Тогда как второй вектор утверждает, что мы должны «серьезно относиться к ценности не только человеческой жизни, но и конкретных человеческих жизней, что означает проявление интереса к практикам и убеждениям, которые придают им значение» [2]. Как и в случае с Нуссбаум, для Аппийя космополитизм имеет в высшей степени педагогические преимущества и, как и она, он считает, что космополитизм влечет за собой моральную ориентацию, и эта этическая установка возлагает на себя определенные обязанности и ответственность. Однако в своем анализе космополитизма Аппийя делает одно существенное открытие, обозначающее парадокс контркосмополитической аргументации: «Однако, как только вы начинаете предлагать причины игнорирования интересов других, само рассуждение обычно втягивает вас в своего рода универсальность» [2, с. 152153]. То есть когда те, кто хочет занять позицию против космополитизма, формулируют свои доводы, они невольно оказываются в тисках универсального разума. Таким образом, «универсальность» становится тем понятием, которое не только требует своего переосмысления в контексте космополитизма, но и сигнализирует о том, что космополитизм должен обратиться к самокритике собственных предрассудков, а также к признанию и раскрытию своей эпистемиологической точки зрения. Это именно то, что подразумевает под собой рефлексивный космополитизм.

\section{Критическая форма космополитизма}

Тем не менее действительным противником имперского космополитизма можно назвать его критическую форму, которую ясно выразил Вальтер Миньоло, сплетя критическую историю западного колониализма с проницательным анализом ключевых философских фигуры. В своем эссе [11] он иллюстрирует достоинства критического космополитизма, проводя различие между тремя различными глобально-имперскими замыслами и соответствующими космополитическими проектами. Согласно Миньоло, глобальным замыслам испанской и португальской империй с XVI по XVII в. соответствовал космополитизм христианской миссии, то есть космополитизм как евангелизация и христианизация язычников. Замыслам французской и английской империи в XVIII и XIX вв. соответствовала космополитическая миссия распространения цивилизации, то есть космополитизм как окультуривание варваров. Для США транснациональные, глобальные и неоколониальные имперские замыслы в течение XX в. соответствовали космополитической миссии модернизации, то есть космополитизму как модернизации или глобализации до-современного и традиционного [11]. В этом ключе вполне очевидна обоснованность критики в отношении тех способов, которыми определенные воплощения космополитизма явно или неявно потворствовали, оправдывали и узаконивали колониализм, империализм и неоколониализм. Задача критического космополитизма, таким образом, состоит в том, чтобы восстановить и сделать слышимыми и видимыми 
голоса тех местных историй, которые были подчинены и заглушены имперским этосом, который привык прокатываться своей военной мощью по тем, кого он сочтет силой сопротивления. Согласно Миньоло, «критический и диалогический космополитизм как регулирующий принцип требует значительных уступок перед разнообразием как универсальным и космополитическим проектом, в котором каждый участвует, вместо того чтобы быть участником» [11, с. 744]. Таким образом, критический космополитизм ориентирован на форму универсальности, которую Миньоло связывает с разнородностью, сочетанием разнообразия и универсальности. Другими словами, основание и универсальность критического космополитизма - это космополитическое разнообразие и рациональность или, точнее, универсальная рациональность.

В этой связи Джудит Батлер, принимая во внимание характер «перформативного противоречия» (т. е. ожидания дальнейшего уточнения того, во имя чего мы призваны уважать, праздновать и прислушиваться к требованиям других) приводит доводы в пользу универсальности, которая должна быть сформулирована посредством вызовов и через вызовы существующей формулировке этого понятия. И эти вызовы возникают от тех, кто не охвачен этой «универсальностью», кто не имеет права занимать место «кого-то», но тем не менее требует, чтобы универсальное как таковое включало их [4, с. 49]. Следовательно, космополитизм становится космополитическим благодаря разнообразию подчиненных, исключенных других, чужсих и маргинальных. И в этой точке мы подходим к космополитизму-снизу, к космополитизму nодчинённыlx в качестве ответа на имперскую модель этого проекта, что подразумевает универсальность вместе с различием, вместе с историческим сознанием, или, выражаясь языком Миньоло: «разнообразие плюс рефлексивность исторической случайности» [11].

\section{"Демократический повтор»}

Таким образом, посредством рефлективного и критического космополитизма можно заключить, что не существует единого космополитического видения, но есть процесс его достижения через взаимодействие с диалогическим воображением, открывающим пространство взаимного преобразования. В этой связи Сейла Бенхабиб предлагает еще один взгляд на рефлексивный аспект космополитизма. Рассматривая роль государства в международных отношениях, она обращает внимание на парадоксальную ситуацию, в которой национальные государства одновременно утверждаются и отрицаются в игре космополитического права. Национальные государства подписывают международные соглашения, которые разграничивают и ставят под сомнение их собственный суверенитет. В условиях космополитизма суверенные нации универсализируются и исчезают. У них есть необходимая власть, но в то же время она всегда уже ограничена - ограничена космополитическим правовым порядком, под которым подписываются эти страны. Эта диалектическая игра между суверенитетом и космополитическим правом принимает порождающий и преобразующий характер, когда она происходит внутри национального государства. Так, индивидуумы, носители 
космополитических прав, могут бросить вызов ограничениям своей собственной нации из катализирующих процессов самоопределения и политико-правовой трансформации. Иными словами, происходит процесс «демократического повтора» [3, с. 45-80], когда происходит расширение прав и возможностей населения и их политической борьбы, посредством чего люди сами принимают непосредственно на свой счет универсалистские перспективы космополитических норм, чтобы обязать к выполнению последних те формы политической и экономической власти, которые стремятся избежать демократического контроля, отчетности и прозрачности. Переплетение векторов борьбы «демократического повтора» в глобальном гражданском обществе и создание солидарности вне границ государств, включая универсальное право на гостеприимство, которое признает другого как потенциального сожителя, предвосхищают иной вид космополитизма - его грядущую форму.

\section{Лuтература}

1. Julten Abdelhalim. Cosmopolitanism and The Right to be Legal: The Practical Poverty of Concepts. Transcience Journal. 2010. No 1 (1). P. 63-86.

2. Anthony Appiah. Ethics in a World of Strangers. N. Y.: Norton, 2006. 224 p.

3. Seyla Benhabib. Another Cosmopolitanism. OUP USA. 2008. 224 p.

4. Judith Butler. 'Universality in Culture', in For Love of Country? / ed. Martha C. Nussbaum. Beacon Press, 2002. 153 p.

5. Michel Foucault. Commentary of Kant's Anthropology from a Pragmatic Point of View. Semiotext(e). 2008. 160 p.

6. Ulf Hannerz. Two Faces of Cosmopolitanism: Culture and Politics. CIDOB. Barcelona, 2006. 29 p.

7. David Harvey, Cosmopolitanism and the Geographies of Freedom. N. Y.: Columbia University Press, 2009. $352 \mathrm{p}$.

8. Immanuel Kant. Anthropology from a Pragmatic Point of View, trans. Robert Louden. Cambridge: Cambridge University Press, 2006. 288 p.

9. Carl Levy, M. S. Adams (eds.). «Anarchism and Cosmopolitanism». The Palgrave Handbook of Anarchism, Palgrave, 2019. 750 p.

10. Eduardo Mendieta. From imperial to dialogical cosmopolitanism // Ethics \& Global Politics. 2009. Vol. 2, No. 3. P. 241-258.

11. Walter Mignolo. The Many Faces of Cosmo-polis: Border Thinking and Critical Cosmopolitanism. Public Culture, 2000. 12 (3). P. 721-748.

12. Torill Strand. The Making of a New Cosmopolitanism // Studies in Philosophy and Education. 2010. 29 (2). P. 229-242.

Статья поступила в редакиию 16.11.2020; одобрена после рецензирования 18.11.2020; принята к публикации 25.11.2020. 


\section{RUINS OF COSMOPOLITAN DISCOURSE}

Aleksandr A. Vlasov

Research Assistant,

Russian State University for the Humanities

Miusskaya Square 6, Moscow 125993, Russia

mioxin@gmail.com

Abstract. The historical ambivalence of the cosmopolitan project and its multifaceted development lead to the breaking up of a single corpus of cosmopolitan discourse into multiple factions of partially contradictory and contrasting approaches that claim to be cosmopolitan. There is more to the fact that cosmopolitanism itself is split into political, economic, moral, legal or cultural, than the Kantian model of cosmopolitan federation reveals more and more critical points of inconsistency with the universalism. At the same time, modernity imposes completely new requirements to understanding the "cosmopolitan" and, thus, breaks the original core, and deconstructs the classical base of concepts around cosmopolitanism.

Keywords: universalism; imperial cosmopolitanism; critical cosmopolitanism; cosmopolitanism of subordinates; democratic replay; performative contradiction; discourse. 